\title{
INTERFERÊNCIA MICROCLIMÁTICA NA UTILIZAÇÃO DO TELHADO VERDE PARA REGIÕES TROPICAIS: ESTUDO DE CASO EM CUIABÁ, MT
}

\author{
Karyna de Andrade Carvalho Rosseti \\ Professora do Departamento de Arquitetura e Urbanismo/FAET/UFMT, Doutoranda no Programa de Pós- \\ Graduação em Física Ambiental, Linha de Pesquisa: Análise Microclimática de Sistemas Urbanos, E-mail: \\ karyna.rosseti@gmail.com \\ Marta Cristina de Jesus Albuquerque Nogueira \\ Professora do Departamento de Arquitetura e Urbanismo/FAET/UFMT, Professora do Programa de Pós- \\ Graduação em Física Ambiental, Linha de Pesquisa: Análise Microclimática de Sistemas Urbanos, E-mail: \\ mcjanp@gmail.com \\ José de Souza Nogueira \\ Professor do Departamento de Física/ IF/ UFMT e Coordenador do Programa de Pós-Graduação em Física \\ Ambiental, E-mail: nogueira@ufmt.br
}

http://dx.doi.org/10.5902/223611707702

\section{RESUMO}

Este artigo tem por objetivo geral avaliar a interferência da cobertura vegetada no micro clima do ambiente construído, analisando seu potencial na modificação dos valores de temperatura e umidade relativa do ar do entorno da edificação. Para isso foi utilizado um protótipo de $5 \mathrm{~m}^{2}$, construído com tijolo de oito furos, reboco e cobertura de fibrocimento, no qual foi instalada a cobertura vegetada. O protótipo foi monitorado durante 15 dias consecutivos da estação do verão e do inverno, no período compreendido entre os dias 05 e 20 de fevereiro (verão) e 06 e 20 de julho (inverno), no ano de 2009. Foram coletados simultaneamente dados de umidade relativa e temperatura do ar no entorno próximo ao protótipo e em um local afastado, ambos apresentando as mesmas características morfológicas. A partir dos resultados encontrados concluiu-se que os efeitos da cobertura verde no microclima estão intimamente associados a presença de água na cobertura.

Palavras-chave: Cobertura vegetada, Conforto ambiental, Sustentabilidade, Clima urbano.

\section{MICROCLIMATIC INTERFERENCE USING THE GREEN ROOF IN TROPICAL REGIONS, CASE STUDY IN CUIABÁ, MT}

\section{ABSTRACT}

This article aims to evaluating the interference of green roofs on microclimate of the built environment, analyzing their potential in modifying the values of temperature and relative humidity of the air surrounding the building. For this were used a prototype of $5 \mathrm{~m}^{2}$, constructed of brick and cement, finished with plaster and roofed with fibre cement, where was installed the green roof. The prototype was monitored for 15 consecutive days of the summer and winter seasons, starting on February 5th, 2009 and ending on February 20th, 2009, between 8:00 a.m. and 6:00 p.m.. Were collected simultaneously data of relative humidity and air temperature in the surroundings near the prototype and in a remote location, both presenting the same 
Rev. Elet. em Gestão, Educação e Tecnologia Ambiental (e-ISSN: 2236-1170)

morphological characteristics. From the results it is concluded that the effects of green roof on the microclimate are closely associated with the presence of water on the roof.

Keywords: Vegetated coverage, Environmental comfort, Sustainability, Urban climate.

\section{INTRODUÇÃO}

Desde o início da existência humana, o homem tem claramente a intenção de alterar o seu microclima, protegendo-se das condições climáticas extremas. Mesmo nas primeiras evidências de casas neolíticas ficam claras as transformações do ambiente natural para se adaptar as necessidades humanas (BENEVOLO, 1980). Com a Revolução Industrial, a ação antrópica começou a tomar proporções jamais vistas, caracterizada pala rápida e significativa expansão dos espaços urbanos (ALEXANDRI \& JONES, 2008).

A urbanização altera as propriedades térmicas do solo, provoca mudanças no balanço de energia na superfície, na circulação do ar atmosférico, gera uma grande quantidade de calor residual das ações humanas, e leva a uma série de mudanças no ecossistema urbano (HUANGA et al., 2009).

Essas mudanças têm um efeito direto sobre o clima local das cidades, especialmente as partes centrais mais adensadas, causando um aumento significativo da temperatura do ar e outras alterações conhecidas como os efeitos de ilha de calor. Isso pode resultar em desagradáveis condições climáticas locais e até mesmo colocar em perigo a saúde humana, especialmente para as cidades com climas quentes (KOPPE et al., 2004; WHITE et al., 2001).

$\mathrm{Na}$ maioria dos espaços urbanos, grande parte das vegetações existentes está concentrada em parques ou espaços de recreio. Apesar de os parques conseguirem diminuir as temperaturas na sua proximidade (SANTAMOURIS, 2001; DIMOUDI \& NIKOLOPOULOU, 2003; BRUSE \& FLEER, 1998; GIRIDHARAM et al., 2004), eles são termicamente incapazes de afetar os espaços com adensamento construtivo onde as pessoas vivem, trabalham e passam a maior parte de sua vida. Os telhados verdes são uma importante ferramenta de planejamento que pode ser usada para ajudar os centros urbanos face às alterações climáticas e melhorar a qualidade de vida nas cidades.

Brownlie (1990) descreve um telhado jardim como "uma área de plantações ornamentais geralmente com um substrato natural, isolado do solo por uma estrutura feita pelo homem, de pelo menos uma andar".

Os telhados verdes têm demonstrado vários benefícios ambientais em várias escalas. $\mathrm{Na}$ escala individual pode resultar em um aumento da vida útil do telhado (Kosareo \& Ries, 2007), um isolamento térmico que conduz a uma redução de gastos com resfriamento no verão e com aquecimento no Inverno (Sailor, 2008) e uma atenuação dos níveis de ruído dentro e fora do ambiente construído (VAN RENTERGHEM \& BOTTELDOOREN, 2009). Os telhados verdes podem melhorar o ambiente local, fornecendo habitat para a biodiversidade (Brenneisen, 2006), podem reduzir os fluxos de águas pluviais (Vanwoert et al., 2005; Carter \& Jackson, 2007) e melhorar a qualidade do escoamento da água do telhado (Berndtsson et al., 2006), além de não interferir no desenho urbano, não necessitando de espaço adicional uma vez que já fazem parte do edifício.

Em larga escala ainda podem reduzir o efeito de ilha de calor urbano (UHI), através de resfriamento devido ao aumento da evapotranspiração, reduzindo assim o consumo de energia e 
Rev. Elet. em Gestão, Educação e Tecnologia Ambiental (e-ISSN: 2236-1170)

as emissões de dióxido de carbono (SKINNER, 2006; ALEXANDRI \& JONES, 2008). Eles também podem seqüestrar carbono (GETTER et al., 2009).

Nas duas últimas décadas tem havido uma expansão significativa da utilização dos telhados verdes na Europa Ocidental e América do Norte, principalmente através da conversão de edifícios existentes (OBERNDORFER et al., 2007).No entanto, esta expansão tem sido largamente restrita às regiões temperadas do hemisfério norte. Em regiões que não estão familiarizadas com telhados verdes, como o Brasil, continuam a existir muitas barreiras potenciais à sua adoção mais generalizada.

As barreiras incluem a falta de normas, custos elevados pela falta de mão de obra especializada, e a falta de pesquisas relevantes e confiáveis para fornecer confiança nos benefícios econômicos e ambientais dos telhados verdes (DUNNETT, 2006; PANTALEÃO \& BURTON, 2006). A última barreira é particularmente relevante para países como o Brasil, é o fato de o clima ser muito diferente das regiões temperadas do hemisfério norte, onde os telhados verdes são mais comuns. Baseando-se nas pesquisas desenvolvidas no hemisfério norte, a experiência e a tecnologia é problemática, devido as diferenças significativas na precipitação, temperatura, substratos disponíveis e vegetação adequada. Isso pode apresentar níveis inaceitáveis de riscos e gastos desnecessários para o desenvolvimento de projetos considerando telhados verdes.

Este estudo tem por objetivo geral desenvolver uma cobertura verde no município de Cuiabá/ MT de forma a analisar as suas restrições de adaptação ao clima local e avaliar a interferência desta cobertura no micro clima do ambiente construído, analisando seu potencial na modificação dos valores de temperatura e umidade relativa do ar do entorno da edificação.

\section{COBERTURAS VERDES}

$\mathrm{Na}$ literatura podemos encontrar dois tipos de coberturas verdes, aquelas que possuem baixa espessura de substrato, ou seja, leves, sendo denominadas como "coberturas verdes extensivas", e as com grande espessura de substrato sendo denominadas "coberturas verdes intensivas" (ROSENZWEIG; GAFFI; PARSHALL, 2006).

Segundo Johnston \& Newton (2004), entre as vantagens encontradas no sistema intensivo podemos destacar a criação de um espaço para o estabelecimento da diversidade da fauna e da flora, e a possibilidade de se cultivar alimentos. No entanto este sistema é complexo e exige grande manutenção, apresenta um elevado peso estrutural e ainda caracteriza-se por altos custos de instalação e manutenção.

O sistema extensivo não tem grandes necessidades quanto a irrigação, podas e fertilização, possui flexibilidade em relação a inclinação da cobertura, apresenta um baixo peso estrutural, pode ser implementado em edificações existentes e possui um custo relativamente baixo. No entanto não permite acessos para espaços de contemplação e recreação e ainda permite uma escolha limitadas de espécies vegetais (JOHNSTON \& NEWTON, 2004).

O objeto de estudo deste trabalho se caracteriza por uma telha vegetada, constituída por um módulo de uma estrutura de telhado verde, que inclui na sua composição uma camada de vegetação. É um conjunto formado pelo substrato rígido mais um substrato leve. A telha vegetada agrega nutrientes essenciais que proporcionam a retenção de água e drenagem do excedente, evitando assim a erosão. Pode ser transportada com grande facilidade, já vem plantada e enraizada, pronta para o uso.

Possui uma largura de $30 \mathrm{~cm}$, um comprimento de $67 \mathrm{~cm}$ e uma espessura de $6 \mathrm{~cm}$, totalizando aproximadamente quatro telhas por metro quadrado. As plantas são perenes, não 
necessitam de regas constantes ou poda. Uma vez por ano, se necessário, deve-se retirar algumas ervas trazidas pelos pássaros.

Uma criteriosa seleção de plantas permite que cobertura vegetada tenha sucesso em condições adversas. Utilizam-se principalmente plantas que desenvolveram um metabolismo chamado "Metabolismo Ácido das Crassulaceas" CAM.

\section{MATERIAIS E MÉTODOS}

\subsection{Materiais}

Os equipamentos utilizados nesta pesquisa foram duas estações micrometeorológicas automáticas,compostas pelo Conjunto de Sensores Integrados (ISS) modelo Vantage Pro 2 Plus, da marca Davis Instruments. O equipamento coleta os dados do tempo e envia-os para o console da Vantage Pro2. O wireless ISS é alimentado por energia solar e envia os dados para o console via ondas de rádio de baixa intensidade.

\subsection{Método}

A metodologia adotada para a realização desta pesquisa caracterizou-se primeiramente pela escolha do local para a instalação das telhas vegetadas. Eram necessários dois protótipos nos quais em um seriam colocadas as telhas vegetadas e o outro caracterizaria um elemento de controle, no qual seria mantida a cobertura original. Os protótipos precisavam ter dimensões próximas de $5 \mathrm{~m}^{2}$ para poder viabilizar a instalação da cobertura, visto que a execução da telha se processaria de forma artesanal.

Levantamentos realizados dentro do campus da UFMT levantaram algumas edificações utilizadas pela instituição como abrigos para as bombas de sucção das cisternas, responsáveis pelo abastecimento de água da Universidade. A escolha dos dois abrigos selecionados (Figura 1) fundamentou-se no fato de eles estarem construídos próximos um do outro, o que caracteriza uma mesma realidade de entorno. Além disso eles têm as mesmas dimensões, com uma área de cobertura de aproximadamente $5 \mathrm{~m}^{2}$.

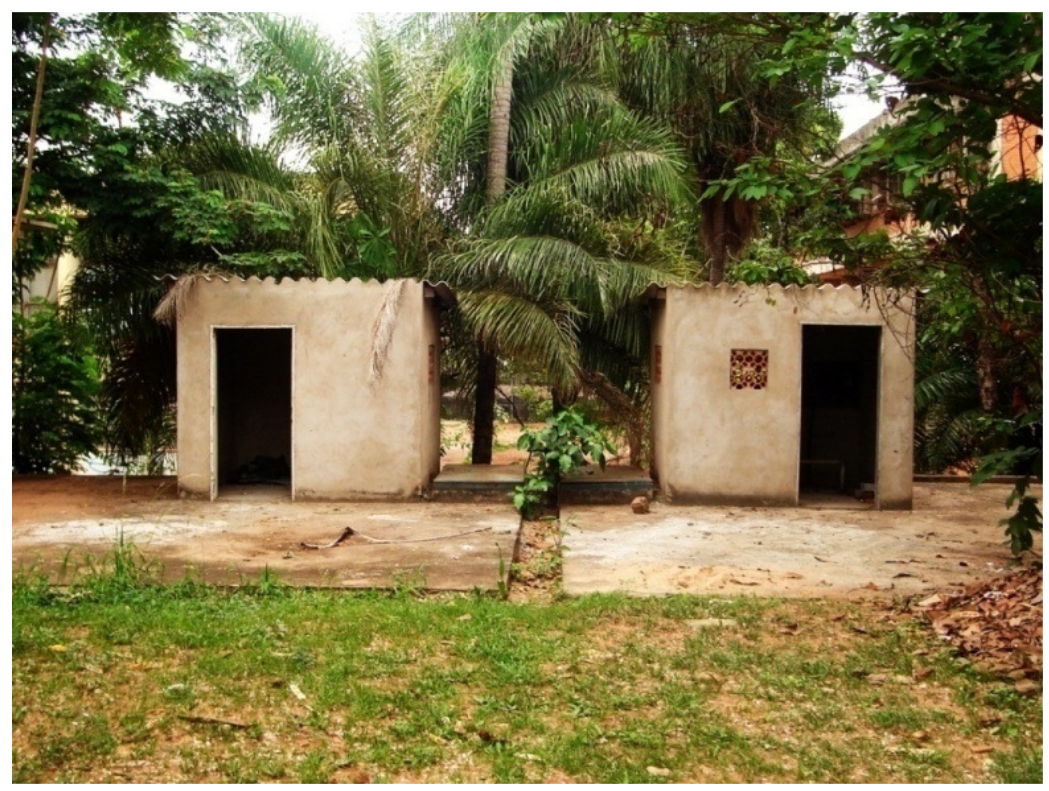

Figura 1 - Protótipos selecionados no campus da UFMT 
Para a execução das placas de concreto, utilizadas como suporte físico da vegetação, foi necessário inicialmente um projeto detalhado das fôrmas de molde para a concretagem, visto que a confecção realizou-se de forma artesanal.

O concreto fabricado possuía flocos de isopor (EPS), em substituição as britas, convencionalmente utilizadas. A escolha do traço mais adequado fez-se através de testes utilizando diferentes sugestões disponíveis no site http://www.megatherm.com.br/portgs/isopor.htm. O peso foi o fator determinante para a escolha do traço, sendo utilizado uma densidade nominal de $700 \mathrm{~kg} / \mathrm{m} 3$, com um peso de $7 \mathrm{~kg}$ aproximadamente. 0 concreto era retirado da fôrma depois de 48 horas do início da cura. Foram confeccionadas um total de 22 placas de concreto.

Foi realizado um método de plantio simples, o meio de cultura foi preparado utilizando-se terra e adubos naturais, com pedaços de madeira, palha de arroz e vegetal seco, para garantir maior leveza. As espécies escolhidas para o povoamento das telhas foram a Alternanthera sp (Periquito vermelho e Periquito prata) e a Cuphea sp (Erica).(Figura 2a)

Antes de receber as telhas a cobertura foi revestida com uma lona impermeabilizante. Não foi necessário um sistema de drenagem pelo fato de a cobertura possuir um beiral para onde toda a água era escoada.(Figura $2 b$ )

Juntamente com as telhas, foi instalado um sistema de irrigação a base de mangueiras perfuradas conectadas a uma torneira localizada a alguns metros do protótipo. A irrigação era realizada todos os dias às $7 \mathrm{hs}$ e às $18 \mathrm{hs}$ e $30 \mathrm{~min}$ e possibilitava condições ideais de umidade mesmo quando não ocorriam precipitações.

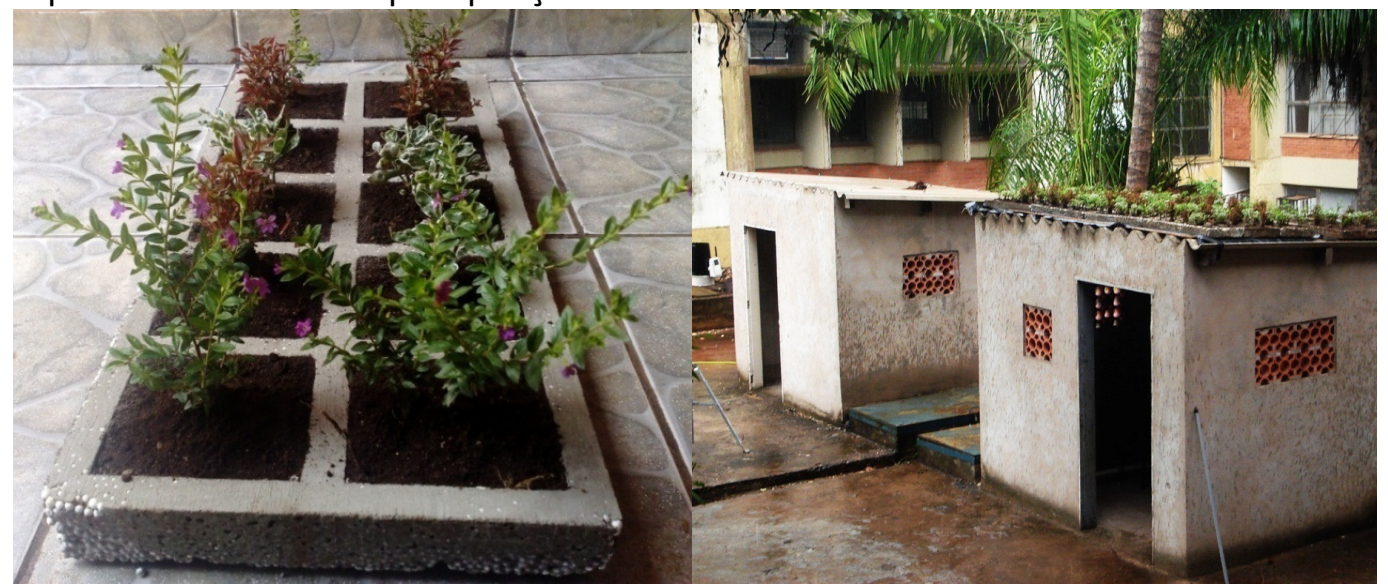

(a) (b)

Figura 2 - Telha após processo de jardinagem (a) e telha instalada no protótipo (b)

O protótipo foi monitorado durante 15 dias consecutivos da estação do verão e do inverno, no período compreendido entre os dias 05 e 20 de fevereiro (verão) e 06 e 20 de julho (inverno), no ano de 2009. As medições se iniciavam às 8 hs e finalizavam às $18 \mathrm{hs}$ de cada dia. Foram coletados simultaneamente dados de umidade relativa e temperatura do ar no entorno próximo ao protótipo, com aproximadamente 1,5m de distância, e em um local afastado, com as mesmas características morfológicas, localizado em frente ao bloco de Pós Graduação em Física Ambiental (PGFA). (Figura 3) 


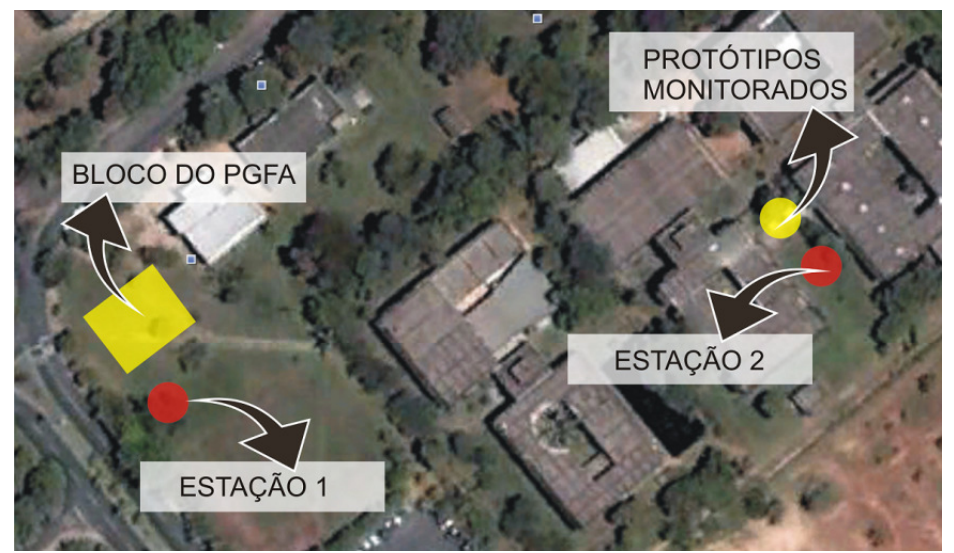

Figura 3 - Localização dos protótipos monitorados, do bloco do PGFA e das Estações 1 e 2

\section{RESULTADOS E DISCUSSÕES}

A temperatura do ar nos dois locais estudados apresenta diferença altamente significativa quando relacionada a estação do ano. No entanto não sofre interferência significativa do local e da relação entre o local e a estação do ano (Tabela 1).

No entanto, quando analisamos o gráfico da temperatura do ar pelo tempo, verificamos na estação do Inverno uma variação no comportamento da temperatura do ar dos dois locais estudados. Na proximidade da cobertura verde, durante a manhã, a temperatura do ar chega a se apresentar $2,26^{\circ} \mathrm{C}$ inferior a temperatura encontrada no PGFA. (Figura 4b) Em contrapartida, durante a tarde o quadro se inverte, podendo ser verificada uma diferença de $2,60^{\circ} \mathrm{C}$ entre a temperatura dos dois locais, sendo a encontrada próxima a cobertura verde mais elevada que a do bloco do PGFA.

Tabela 1 - Análise de Variância, considerando a temperatura do ar como variável

\begin{tabular}{c|c|c|c|c|c|c}
\hline $\begin{array}{c}\text { Variável } \\
\text { Dependente }\end{array}$ & $\begin{array}{c}\text { Fonte } \\
\text { da } \\
\text { Variação }\end{array}$ & $\begin{array}{c}\text { Soma dos } \\
\text { Quadrados }\end{array}$ & $\begin{array}{c}\text { Graus de } \\
\text { Liberdade }\end{array}$ & $\begin{array}{c}\text { Quadrados } \\
\text { Médios }\end{array}$ & F Calc. & $\begin{array}{c}\text { Nível de } \\
\text { Signif. }\end{array}$ \\
\hline \multirow{2}{*}{$\begin{array}{c}\text { Temperatura } \\
\text { do } \operatorname{Ar}\left({ }^{\circ} \mathrm{C}\right)\end{array}$} & Estação & 2477,833 & 1 & 2477,833 & 157,660 & 0,000 \\
\cline { 2 - 7 } & Local & 16,828 & 1 & 16,828 & 1,071 & 0,301 \\
\cline { 2 - 7 } & $\begin{array}{c}\text { Estação } \\
\text { * Local }\end{array}$ & 43,079 & 1 & 43,079 & 2,741 & 0,098 \\
\hline
\end{tabular}




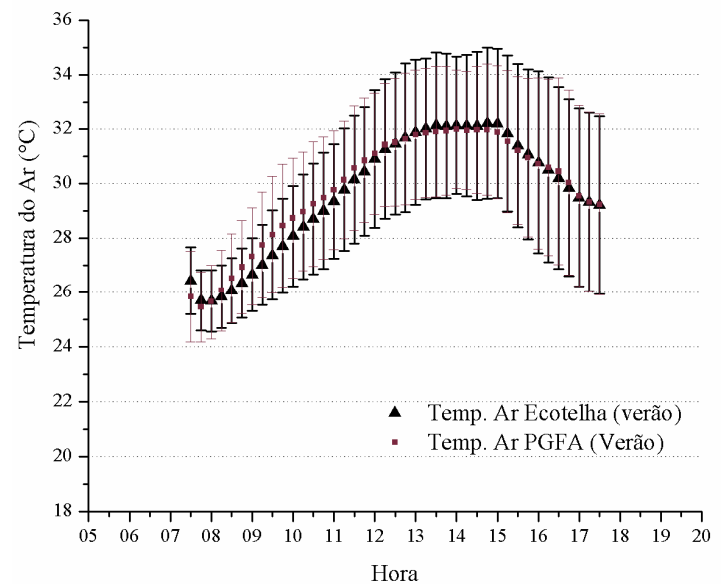

(a)

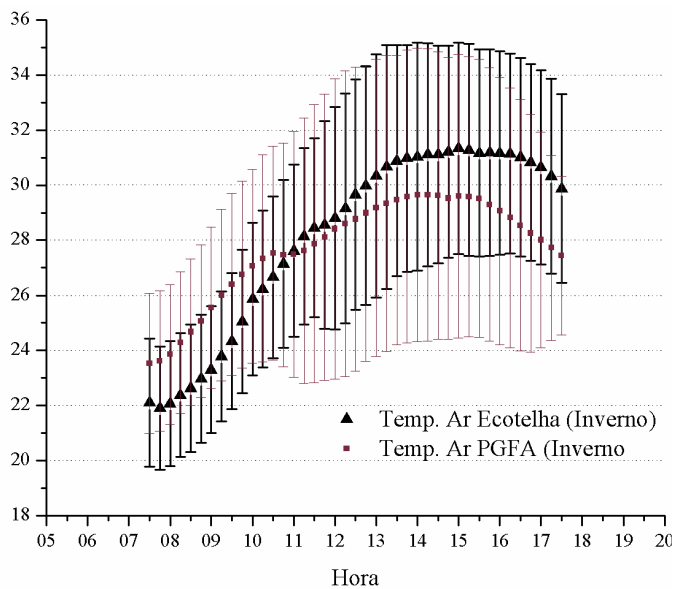

(b)

Figura 4 - Temperatura média do ar nas proximidades da cobertura verde e no bloco do PGFA na estação do verão (a) e na estação do inverno (b)

Na estação do verão não é possível verificar uma diferença muito acentuada entre a temperatura do ar das duas localidades. A maior diferença se dá durante a manhã, podendo ser observadas temperaturas nas proximidades da cobertura verde $0,75^{\circ} \mathrm{C}$ inferiores às encontradas no bloco do PGFA. (Figura 4a)

Quando tratamos da umidade relativa do ar, esta apresenta diferença altamente significativa quando relacionada a todas as fontes de variação tratadas no teste, ou seja, a variável sofre interferência tanto da estação do ano, quanto do tipo de cobertura e ainda da relação entre cobertura e estação do ano. (Tabela 2)

Tabela 2 - Análise de Variância, considerando a umidade relativa do ar como variável dependente

\begin{tabular}{c|c|c|c|c|c|c}
\hline $\begin{array}{c}\text { Variável } \\
\text { Dependente }\end{array}$ & $\begin{array}{c}\text { Fonte } \\
\text { da } \\
\text { Variação }\end{array}$ & $\begin{array}{c}\text { Soma dos } \\
\text { Quadrados }\end{array}$ & $\begin{array}{c}\text { Graus de } \\
\text { Liberdade }\end{array}$ & $\begin{array}{c}\text { Quadrados } \\
\text { Médios }\end{array}$ & F Calc. & $\begin{array}{c}\text { Nível de } \\
\text { Signif. }\end{array}$ \\
\hline \multirow{2}{*}{$\begin{array}{c}\text { Umidade } \\
\text { Relativa do } \\
\operatorname{Ar}\left({ }^{\circ} \mathrm{C}\right)\end{array}$} & Estação & 126169,078 & 1 & 126169,078 & 710,667 & 0,000 \\
\cline { 2 - 7 } & Local & 3648,778 & 1 & 3648,778 & 20,552 & 0,000 \\
\cline { 2 - 7 } & $\begin{array}{c}\text { Estação } \\
* \text { Local }\end{array}$ & 3995,371 & 1 & 3995,371 & 22,505 & 0,000 \\
\hline
\end{tabular}

Na Figura 5, verifica-se na umidade relativa do ar pelo tempo assim como na temperatura média do ar, na estação do inverno, diferenças mais significativas entre as umidades encontradas nos dois locais monitorados. Em praticamente todos os horários do dia a umidade encontrada nas proximidades da cobertura verde encontram-se inferiores as encontradas no bloco do PGFA, chegado a ser observada uma diferença de $12,3 \%$ entre as umidades das duas localidades. (Figura $5 b)$ 


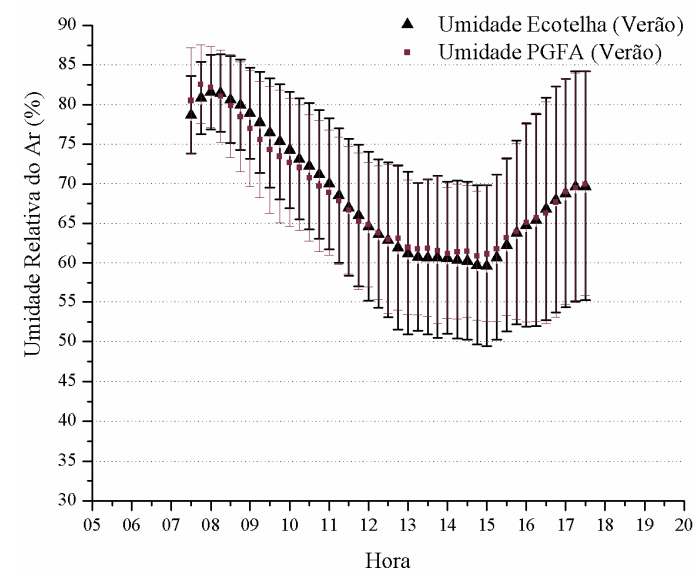

(a)

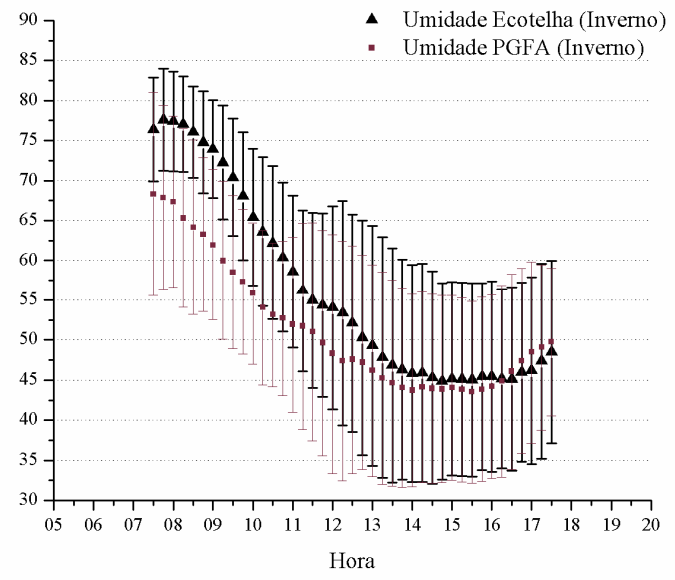

(b)

Figura 5 - Temperatura média do ar nas proximidades da cobertura verde e no bloco do PGFA na estação do verão (a) e na estação do inverno (b)

$\mathrm{Na}$ estação do verão não é possível verificar uma diferença muito acentuada entre a umidade relativa média do ar das duas localidades. As maiores umidades oscilam durante todo o dia entre as duas localidades, o que dificulta a obtenção de qualquer conclusão sobre a interferência da cobertura verde na umidade do ar neste período, (Figura 5a).

A diferença confirmada do teste de variância entre o comportamento da umidade relativa nas duas localidades pode ser facilmente verificada no gráfico da estação do inverno. E o fato de essa característica não poder ser verificado no verão justifica a interação encontrada entre a umidade relativa e a relação da estação do ano com a localidade.

Levando em consideração as características da estação do inverno no clima local pode-se compreender os resultados encontrados. Segundo a classificação de Koppen, o clima de Cuiabá é do tipo AW, também denominado Tropical semi-úmido, possui quatro a cinco meses secos e duas estações bem definidas, uma seca (outono-inverno) e uma chuvosa (primavera-verão).Percebe-se que no período seco, caracterizado pelo inverno, a instalação da cobertura verde criou condições para elevar a umidade relativa a valores próximos aos encontrados na estação chuvosa. Considerando a escassez de água disponível na atmosfera no período do inverno, toda a água utilizada na irrigação do telhado era absorvida rapidamente pelo ar elevando sua umidade relativa. No entanto a medida que os níveis de água na telha iam diminuindo, a umidade do ar também diminuía até se igualar a encontrada em localidades afastadas da cobertura.

No verão, como a ar já se encontrava com umidade elevada, a água presente na telha não causava grandes efeitos na umidade do entorno, fazendo com que as duas localidades estudadas apresentassem valores semelhantes em todos os horários do dia.

A redução na temperatura do ar verificada no período matutino na estação seca se deve justamente à evapotranspiração da vegetação existente na cobertura. Quase toda a água tomada pela planta é perdida através da transpiração e uma fração menor é usada pela planta para seu metabolismo. Juntos, esses processos são referidos como evapotranspiração, ela esfria o ar, usando o calor presente do ar para evaporar a água disponível no meio (SIMPSON \& MCPHERSON, 2001; MITCHELL et al., 2007).

As consequências deste processo são justamente um aumento na umidade relativa do ar pela evaporação da água, e uma redução na temperatura do ar pela captura da energia térmica do meio, necessária para promover a mudança de fase da água. 
Segundo Moffat e Schiller (1981), o mecanismo mais importante de contribuição para a redução das altas temperaturas nas cidades pela vegetação é a evaporação. Quando a quantidade de energia que uma planta precisa para lidar com o elevado grau de probabilidade de evaporação excede a que é fornecida pela radiação solar, a planta utiliza-se do calor da atmosfera, causando a redução da temperatura do ar (JONES, 1992).

\section{CONCLUSÃO}

Observa-se que para a manutenção da vegetação no clima local são necessárias irrigações diárias principalmente nos períodos de estiagem. Verifica-se ainda que os efeitos da cobertura verde no microclima estão intimamente associados a presença de água na cobertura, utilizada no processo de evapotranspiração.

A presença da cobertura verde é capaz de otimizar as condições de conforto térmico no entorno da construção, elevando os níveis de umidade relativa e reduzindo a temperatura do ar, nas estações secas. Nas estações úmidas não verificam-se interferências significativas da cobertura no microclima do entorno.

\section{RECOMENDAÇÕES}

Recomenda-se o estudo de outras espécies vegetais e outros substratos que sejam capazes de manter a cobertura úmida por um maior intervalo de tempo. Além disso verifica-se a necessidade de se ampliar o experimento de forma a abranger uma edificação com condições reais de ocupação humana, buscando assim quantificar as interferências que a colocação de um telhado verde provoca no micro clima da área construída e do local no qual esta construção se insere.

\section{AGRADECIMENTOS}

À ELETROBRÁS e CAPES pelo apoio financeiro utilizados na pesquisa.

\section{REFERÊNCIAS BIBLIOGRÁFICAS}

(VANWOERT, N.D., ROWE, D.B., ANDRESEN, J.A., RUGH, C.L., FERNANDEZ, R.T. AND XIAO, L. Green roof stormwater retention: effects of roof surface, slope, and media depth, Journal of Environmental Quality 34, p. 1036-1044. 2005.

ALEXANDRI, E., JONES, P. Temperature decreases in an urban canyon due to green walls and green roofs in diverse climates. Building and Environment, 43 (4), p. 480-493. 2008.

BENEVOLO, L. The history of the city, Scholar Press. London. 1980.

BERNDTSSON , J.C., EMILSSON, T. AND BENGTSSON, L. The influence of extensive vegetated roofs on runoff water quality. Science of the Total Environment, 355, p. 48-63. 2006.

BRENNEISEN, S. Space for urban wildlife: designing green roofs as habitats in Switzerland, Urban Habitats, 4, p. 27-36. 2006.

BROWNLIE, I. Principles of public international law. 4 ed., New York, 748p. 1990.

BRUSE, M. AND FLEER, H. Simulating surface-plant-air interactions inside urban environments with a three dimensional numerical model. Environmental Modelling and Software, 13, p. 373384. 1998. 
CARTER, T. AND JACKSON, C.R. Vegetated roofs for stormwater management at multiple spatial scales. Landscape and Urban Planning 80, p. 84-94. 2007.

DAVIES, R.E., KNAPPENBERGER, P.C., NOVICOFF, W.M. AND MICHAELS, P.J. Decadal changes in summer mortality in US cities. International Journal of Biometeorology 47, p. 166-175. 2003.

DÍAZ, J., BALLESTER, F. AND LÓPEZ-VÉLEZ, R. Impacts on human health. In: J.M. Moreno Rodríguez. $(E d)$. The preliminary assessment of the impacts in Spain due to effects of climate change, project ECCE, Ministry of the Environment, Madrid. 2005.

DIMOUDI, A. AND NIKOLOPOULOU, M. Vegetation in the Urban Environment: Microclimatic Analysis and Benefits. Energy and Buildings, 35 (1), p. 69-76. 2003.

DUNNETT, N. Sheffield's Green Roof Forum: a multi-stranded programme of green roof infrastructure development for the UK's 'greenest city. In: Proceedings of the Fourth Annual Greening Rooftops for Sustainable Communities Conference, Awards and Trade Show. The Cardinal Group, Toronto, Boston. 2006.

GETTER, K.L., ROWE, D.B., ROBERTSON, G.P., CREGG, B.M. AND ANDRESEN, J.A. Carbon sequestration potential of extensive green roofs, Environmental Science and Technology 43, pp. 7564-7570. 2009.

GIRIDHARAM, R., GANASAN, S. AND LAU, S.S.Y. Daytime urban heat island in high-rise and highdensity residential developments in Hong Kong, Energy and Buildings 36, pp. 525-534. 2004.

GRANT, G., ENGLEBACK, L., NICHOLSON, B. Green roofs: existing status and potential for conserving biodiversity in urban areas. English Nature Research Report n. 498. Peterborough, U.K.: English Nature. 2003.

HUANGA, S., TANIGUCHIB, M., YAMANOC, M. AND WANGD, C. Detecting urbanization effects on surface and subsurface thermal environment. Human Impacts on Urban Subsurface Environments, 407(9), pp. 3142-3152. 2009.

JOHNSTON J, NEWTON J. Building green: a guide to using plants on roofs, walls and pavements. London (UK): Greater London Authority. 2004.

JONES, H.G. Plants and microclimate. Cambridge University Press, Cambridge. 1992.

KOPPE,C., KOVATS, S., JENDRITZKY, G. AND MENNE, B. Health and global environmental change; heat-waves: risks and responses. Series no. 2, Energy, Environment and Sustainable Development. World Health Organization, Copenhagen. 2004.

KOSAREO, L. AND RIES, R. Comparative environmental life cycle assessment of green roofs, Building and Environment 42, pp. 2606-2613. 2007.

MITCHELL, V.G., CLEUGH, H.A., GRIMMOND, C.S.B. AND XU, J. Linking urban water balance and energy balance models to analyse urban design options. Hydrological Processes. 22 (16), pp. 2891-2900. 2007.

MOFFAT, A.S. AND SCHILER, M. Landscape design that saves energy New York. William Morrow and Company, Inc, New York. 1981.

OBERNDORFER, E., LUNDHOLM, J., BASS, B., COFFMAN, R.R., DOSHI, H., DUNNETT, N., GAFFIN, S., KOHLER, M., LIU, K.K.Y. AND ROWE, B. Green roofs as urban ecosystems: ecological structures, functions, and services, Bioscience 57, pp. 823-833. 2007. 
PANTALONE, J., BURTON, L.Z. Making green roofs happen in Toronto. In: Proceedings of the Fourth Annual Greening Rooftops for Sustainable Communities Conference, Awards and Trade Show. The Cardinal Group, Toronto, Boston. 2006.

ROSENZWEIG C, GAFF S, PARSHALL L. Introduction and study methods. In: Green roofs in the New York metropolitan region - research report. New York (NY): Columbia University, Center for Climate Systems Research, NASA Goddard Institute for Space Studies. 2006.

SAILOR, D.J. A green roof model for building energy simulation programs, Energy and Buildings 40, pp. 1466-1478. 2008.

SANTAMOURIS,M.; Heat-Island Effect. In: Santamouris, M. (Ed). Energy and climate in the urban built environment, James \& James, London. 2001.

SIMPSON, J.R. AND MCPHERSON, E.G. Tree planting to optimize energy and CO2 benefits. In: C. Kollin, Editor, Investing in Natural Capital, Proceedings of the 2001 National Urban Forest Conference, Washington D.C: 5-8. 2001.

SKINNER, C.J. Urban density, Meteorology and Rooftops Urban Policy and Research. 24, pp. 355367. 2006.

SNODGRASS, E.C. AND SNODGRASS, L.L. Green Roof Plants: a Resource and Planting Guide. Timber Press, Portland, OR. 2006.

VAN RENTERGHEM, T. AND BOTTELDOOREN, D. Reducing the acoustical facade load from road traffic with green roofs, Building and Environment 44, pp. 1081-1087. 2009.

WHITE, K. S. ET AL. Technical summary, climate change 2001: impacts, adaptation and vulnerability. In: J.J. McCarthy, O.F. Canziani, N.A. Leary, D.J. Dokken and K.S. White, Editors, Climate change 2001: impacts, adaptation and vulnerability, United Nations' Intergovernmental Panel on Climate Change (IPCC) Cambridge University Press, Cambridge, pp. 19-73. 2001.

Identificação dos Autores:

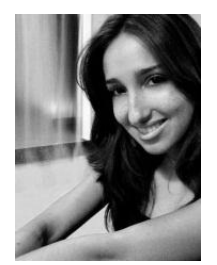

Karyna Andrade Carvalho Rosseti

Graduação em Arquitetura e Urbanismo pela Universidade Federal de Mato Grosso/ UFMT

Professora Efetiva do Departamento de Arquitetura e Urbanismo/ UFMT;

Doutoranda pelo Programa de Pós Graduação em Física Ambiental/ PPGFA/ UFMT, Linha de Pesquisa: Análise

Microclimática em Sistemas Urbanos, E-mail: karyna.rosseti@gmail.com 


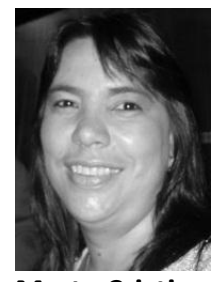

Marta Cristina de Jesus Albuquerque Nogueira

Graduação em Engenharia Civil pela Universidade Federal de Mato Grosso/ UFMT;

Professor Efetiva do Departamento de Arquitetura e Urbanismo/ UFMT;

Professora do Programa de Pós Graduação em Física Ambiental/ PPGFA/ UFMT, Linha de Pesquisa: Análise Microclimática em Sistemas Urbanos, E-mail: mcjanp@gmail.com

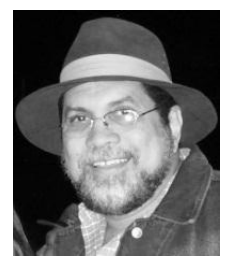

José de Souza Nogueira

Graduação em Licenciatura Plena em Física pela Universidade Federal de Mato Grosso/ UFMT;

Professor Efetivo do Instituto de Física/ UFMT;

Professor do Programa de Pós-Graduação em Física Ambiental e Coordenador do Programa de Pós-Graduação em Física Ambiental em nível de Mestrado e Doutorado, E-mail: nogueira@ufmt.br 